Provided for non-commercial research and education use. Not for reproduction, distribution or commercial use.

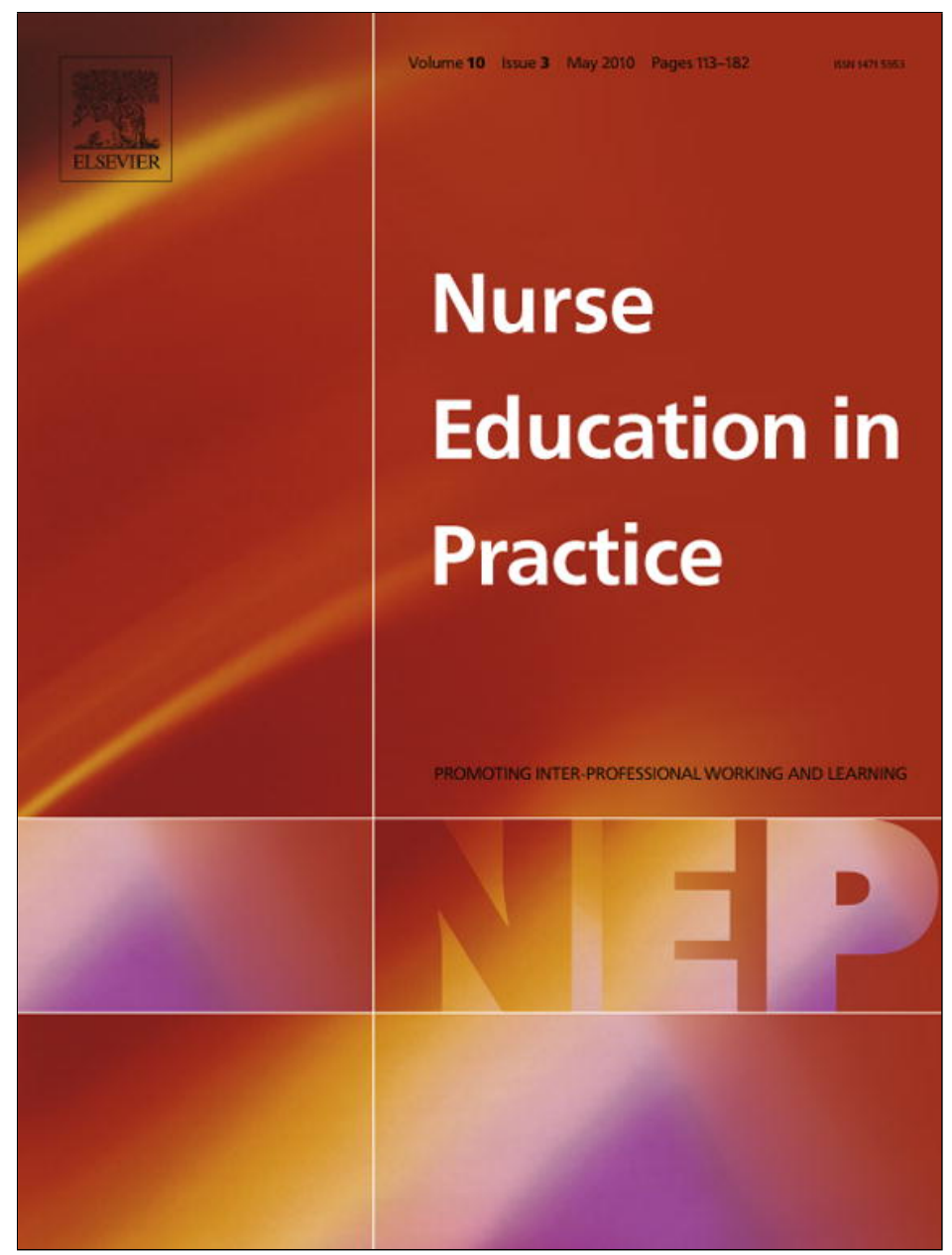

This article appeared in a journal published by Elsevier. The attached copy is furnished to the author for internal non-commercial research and education use, including for instruction at the authors institution and sharing with colleagues.

Other uses, including reproduction and distribution, or selling or licensing copies, or posting to personal, institutional or third party websites are prohibited.

In most cases authors are permitted to post their version of the article (e.g. in Word or Tex form) to their personal website or institutional repository. Authors requiring further information regarding Elsevier's archiving and manuscript policies are encouraged to visit:

http://www.elsevier.com/copyright 


\title{
Supporting disabled students in practice: A tripartite approach
}

\author{
Lauren Griffiths $^{\mathrm{a}, *}$, Piers Worth ${ }^{\mathrm{b}, 1}$, Zoe Scullard ${ }^{\mathrm{a}, 2}$, Davina Gilbert ${ }^{\mathrm{c}, 3}$ \\ ${ }^{a}$ Faculty of Society and Health, Buckinghamshire New University, Chalfont Campus, Gorelands Lane, Chalfont St Giles, Buckinghamshire HP8 4AD, United Kingdom \\ ${ }^{\mathrm{b}}$ Buckinghamshire New University, High Wycombe Campus, Queen Alexandra Road, High Wycombe, Buckinghamshire HP11 3JZ, United Kingdom \\ ${ }^{\mathrm{c}}$ Directorate of Nursing, 2nd Floor Education Centre, Charing Cross Hospital, Imperial College Healthcare NHS Trust, London W6 8RF, United Kingdom
}

\section{A R T I C L E I N F O}

\section{Article history:}

Accepted 4 May 2009

\section{Keywords:}

Nursing

Disability

Practice learning

Partnership working

Reasonable adjustment

\begin{abstract}
S U M M A R Y
Universities are required to make reasonable adjustments for disabled students. For providers of professional courses, in this case pre-registration nursing, this requirement is perceived to pose significant challenges. In part this is due to the nature of the course, where practice learning is a central component and therefore clinical hands-on experience of the care of patients/clients is an absolute requirement. Concerns around the ability of disabled students' to meet the programme requirements have been expressed.

This article describes the co-development of a six-phase tripartite model that provides a supportive framework for disabled student nurses in the practice environment. A brief overview of the literature will be given and a single case study will be used to demonstrate the model in action. The development of broad partnership working between the Practice Learning Team, The Disability Service and the Student Placement Facilitator, taking a student centric approach, is outlined. Finally, the process by which a critical knowledge base, on which decisions around reasonable adjustment can be made is discussed.
\end{abstract}

(c) 2009 Elsevier Ltd. All rights reserved.

\section{Introduction}

The number of students with disabilities entering Higher Education, nationally and internationally, is increasing year-on-year (Higher Education Statistics Agency (HESA), 2009) (Fleming, 2005; Ashcroft et al., 2008), with 6.8\% of undergraduate students having disclosed a disability (HESA, 2009). It is not surprising, therefore, that there are a number of healthcare students with a range of disabilities accepted onto professional higher educational programmes (Ijiri and Kudzma, 2000; Konur, 2002; Wright and Eathorne, 2003). Within our faculty, the disabled student ratio is much higher with 1 in 10 having some form of disability (Buckinghamshire New University, 2007). This poses unique and sometimes complex challenges for the faculty and our practice partners. However, under the Disability Discrimination Act (DDA) (Her Majesty's Stationary Office (HMSO), 1995; HMSO, 2005), the University is required to make reasonable adjustments to meet the needs of disabled students and in such a way that is non-discriminatory (Scullion et al., 2002).

\footnotetext{
* Corresponding author. Tel.: +44 01494 603080; fax: +44 01494603182.

E-mail addresses: lauren.griffiths@bucks.ac.uk, lgriff02@bucks.ac.uk (L. Griffiths), piers.worth@bucks.ac.uk (P. Worth), zoe.scullard@bucks.ac.uk (Z. Scullard), davina.gilbert@imperial.ac.uk (D. Gilbert).

1 Tel.: +4401494 522141x5049.

2 Tel.: +44 01494 522141x5764; fax: +4401494 603182 .

3 Tel.: +4402083832541.
}

This article outlines a co-developed six-phase tripartite model of working and describes how collaborative partnerships between the practice team, the disability service and practice partners ensured parity between support strategies available within the university and in practice. The model deals with placement modification through an on-going, dynamic step-by-step process that evolves as the student moves into different practice settings. Such an approach allows practice partners to create an enabling environment for disabled students.

\section{Contextual background}

The Faculty of Society and Health at Buckinghamshire New University provides pre- and post-registration nursing, diploma and degree, and social work programmes for NHS London in North West London. Our annual intake of pre-registration student nurses, for the Adult, Mental Health and Child Health branch, is 420, with two intakes per academic year; September and February. The practice placement circuit is comprised of five NHS Trusts, three NHS Primary Care Trusts and a large number of independent and private sector placements across North West London and South Buckinghamshire. The pre-registration team consists of 27 lecturers with a designated Practice Learning Team, a Portfolio Leader for Practice Learning and a Lead for Practice Learning. A well-established link lecturer network exists to support practice areas. The pre-registration team is supported by a further 47 post-registration lecturers who provide specialist input and support for pre-registration students in practice. 
Over the last 2 years, members of the Pre-registration Team have noted an increase in the number and complexity of declared disabilities (Buckinghamshire New University, 2007). Within the DDA (HMSO, 1995, p. 2), disability is defined as 'a physical or mental impairment which has a substantial and long-term adverse effect on a person's ability to carry out normal day-to-day activities'. This definition is strikingly broad and illustrates how easily these disabilities might be present in our study or working environment, albeit hidden. The most common types of disability encountered within our student population are dyslexia, dyspraxia, dyscalculia, anxiety, physical impairments, hearing deficits, progressive and long-term medical conditions and mental health concerns. This growing awareness of the needs of disabled students, particularly in practice, prompted the practice team to explore the available evidence in order to inform the development of a supportive model based on the principles of enablement and partnership working.

\section{Literature review}

Much of the literature explores the impact of the various Disability Discrimination Acts on nurse education programmes in the United States, Australia, Canada and the UK (Magilvy and Mitchell, 1995; Konur, 2002; Selekman, 2002; Ryan and Struhs, 2004; Sanderson-Mann and McCandless, 2006; Ashcroft et al., 2008). Strategies to support students, particularly from an academic stance tend to concentrate on learning disabilities, such as dyslexia (Selekman, 2002; Roberts and Mitchell, 2005; Sanderson-Mann and McCandless, 2006; White, 2007). Furthermore, there is limited literature detailing strategies for specific types of disabilities, such as attention hyperactivity disorder (Bradshaw and Salzer, 2003) and visual impairment (Atkinson and Hutchinson, 2005).

The lack of empirical data, particularly in terms of the challenges the disabled students face in practice (Wright, 2000), has led to anecdotal rhetoric as to their suitability to fulfil clinical roles (Wiles, 2001; Watkinson, 2002). However, there is no evidence to substantiate this claim (Sowers and Smith, 2002). The Disability Rights Commission (DRC) in their recent report, Maintaining Standards: Promoting Equality (DRC, 2007) has presented universities, the Nursing \& Midwifery Council (NMC) and the National Health Service (NHS) with challenging research findings. The report illustrates the difficulties faced by disabled students seeking to train or work as an NHS professional. Furthermore, the DRC (2007) argues that the healthcare environment is one where individuals are reluctant to disclose a disability. For example, they may choose to conceal their disability as there is a discriminatory culture within healthcare that upholds the notion that disabled practitioners represent a danger to patient safety (Maheady, 2003; Morris and

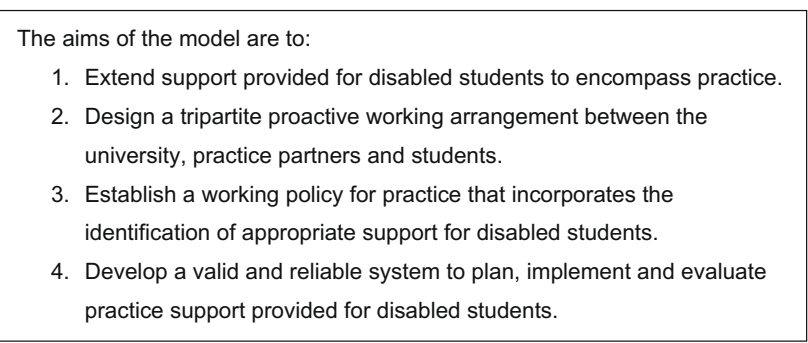

Fig. 2. Aims of the tripartite model of working.

Turnbull, 2006). However, the DRC (2007) argue that many of the assumptions and stereotypes that appear to exist in the NHS and the nursing profession about disabled individuals being potentially unsafe in practice are unjustified in reality.

The lack of reliable and relevant evidence to inform policy and practice has meant that universities, disability services and practice partners, are working without clear direction. There is a paucity of data on which to make critical decisions as to the level and type of support required for disabled students in practice. Ultimately the decision as to whether a student is fit to practice has to rest on whether they are able to provide safe, competent, effective and independent practice at the point of registration (NMC, 2004). The dichotomy between regulatory requirements and disability legislation results in practice partners and universities struggling to reconcile the demands of both (Manthrope and Stanley, 1999; Crawshaw, 2002). However, the Special Educational Needs and Disability Act (SENDA) HMSO, 2001) part IV places a duty upon universities to work in partnership with practice partners to ensure a student centric approach is adopted to lead to a positive practice learning experience(Konur, 2002).

\section{The six-phase tripartite model}

To foster a holistic, student-centric approach to supporting disabled students in practice, a six-phase tripartite model of working was developed. The model relies on the engagement of three key groups: the Practice Team, comprising the Portfolio Leader for Practice Learning; the Lead for Practice Learning; and the Disability Service and a representative from the host trust (in this case the Student Placement Facilitator (SPF)). Students have a responsibility to work alongside the University, the Disability Service and the SPF, to ensure the reasonable adjustments continue to meet their needs. The model enables the Practice Team to work in partnership with a broader range of people to gather and collate relevant information, undertake consultation on behalf of and in collaboration

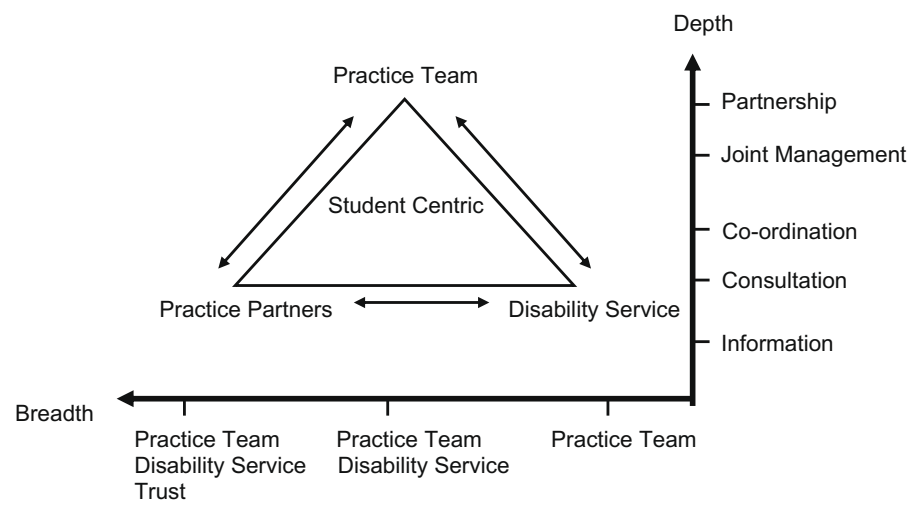

Fig. 1. The tripartite model of working. 
with the student, co-ordinate reasonable adjustment requirements within the practice environment and jointly manage the students practice experience (Fig. 1).

The model was co-designed with specific aims (Fig. 2) and to ensure that appropriate support is provided before, during and after the clinical placement. It is based on the integration of services that are reviewed and modified at all stages of the students programme (Fig. 3). The underlying principle is that support is comparable and seamless to that provided whilst in an academic setting as it was acknowledged that reasonable adjustments made in practice are often not aligned to that provided by the university (Stanley et al., 2007). An important component in ensuring that the Practice Team and Disability Service had similar perspectives around the context of practice involved acquainting the Disability Service advisors with the world of nursing. It was agreed that to do this the Disability Service advisors would spend a day in different practice settings. This allowed the advisors to gain first hand experience of the complexity and challenges such environments pose, which in turn informed future discussions around suitable placements and reasonable adjustments.

\section{Case study - the model in-action}

In order to describe the concepts and processes of the model, a single case example is used. Guidance as to whether ethical approval was required was sought from the University Ethics

\section{Supporting Disabled Students in Practice}

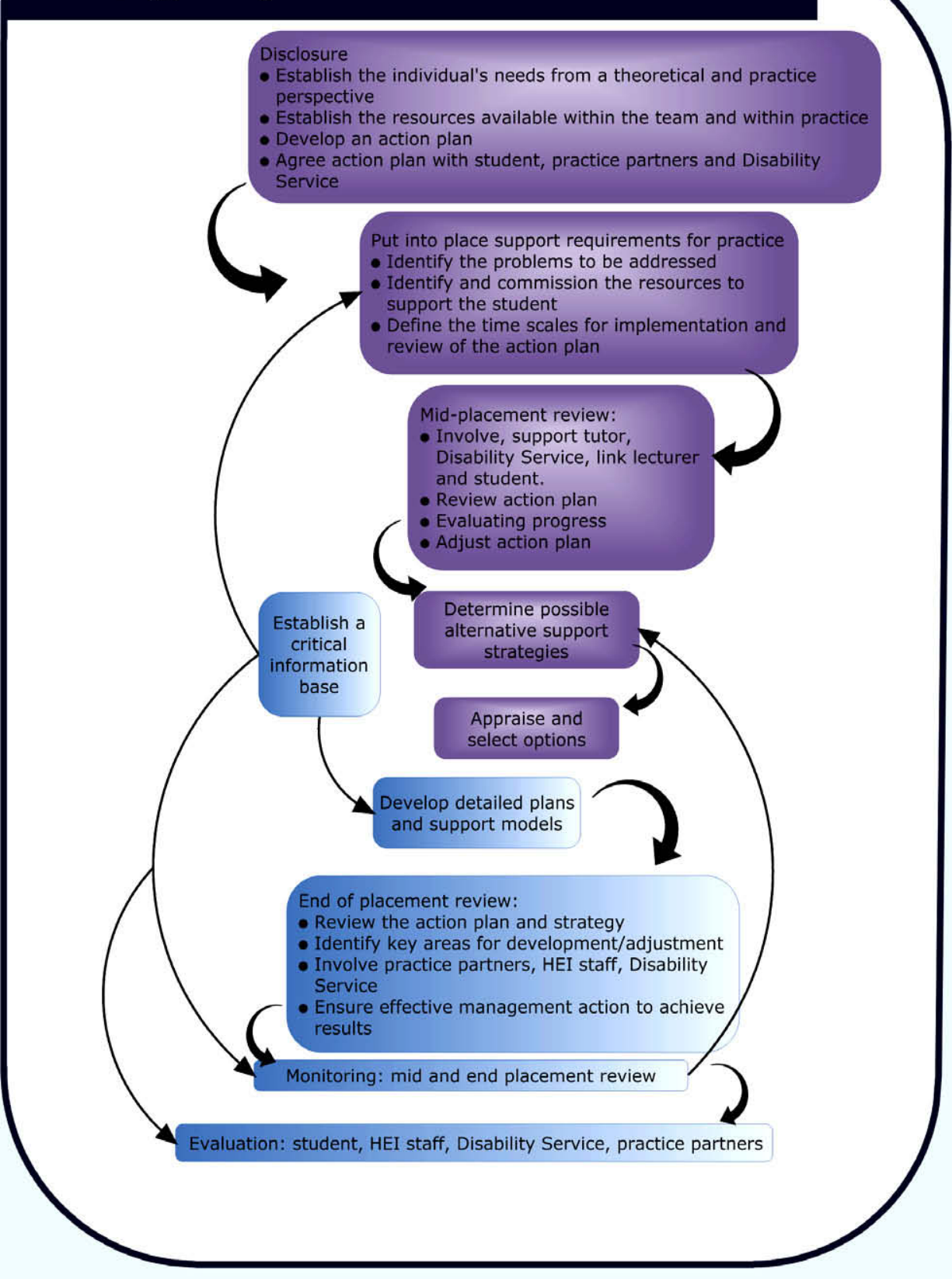

Fig. 3. The tripartite model. 


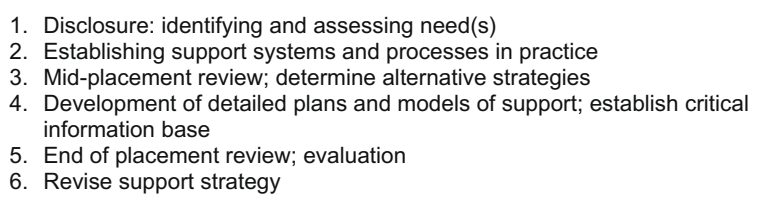

4. Development of detailed plans and models of support; establish critical information base

5. End of placement review; evaluation

6. Revise support strategy

Fig. 4. The tripartite model at a glance.

Committee, who advised that consent from the student was sufficient. Consent was gained from the student and her name and some aspects of her disability changed to ensure anonymity and confidentiality (NMC, 2008). Although the model is designed to be applied in an individualistic way, there are key phases within the framework that are applicable to all disabled students (Fig. 4). Using Helen's student pathway, the six-phase tripartite model will be illustrated.

Helen, a 20-year-old disabled student nurse, provides an ideal example to illustrate the key phases of the model in an applied way. Helen attended a university open day and declared her physical disability, Myalgic Encephalopathy (ME). Helen requested advice as to her suitability to pursue a nursing career. During further discussion with the Practice Learning Lead, Helen highlighted that some days were better than others, with bad days resulting in debilitating fatigue, problems with concentration, pain without swelling in small and large joints and headaches. Such days made it difficult for her to perform daily activities.

\section{Phase 1: disclosure, identifying and assessing need/s}

The University encourages an atmosphere of open disclosure at all stages of the students' journey. Following disclosure at the University open day, a physical assessment of Helen's disability, in terms of her fitness to practice, was arranged. Key to the assessment was whether Helen was able to engage in the core activities of nursing. Helen was invited to attend a nursing skills session at the University in order to undertake a task analysis. This would enable early identification of potential areas that would require reasonable adjustment in practice.

The task analysis included bed making, cardio-pulmonary resuscitation and injection technique. Helen was able to perform the skills without any problems and the assessor was confident that Helen had the appropriate dexterity and strength to perform nursing skills. To complete the assessment Helen was referred to the Occupational Health Department and the Disability Service for further advice and assessment. Following the assessment process Helen was offered an unconditional place on the programme which she accepted.

\section{Phase 2: establish support systems and processes in practice}

The emphasis of this phase is dependant on the student's disability, their specific needs and willingness to engage as an active participant. Key to the initial stages was that a balanced and educative communication of Helen's specific needs was shared confidentially with key individuals involved in her future education and development. A routine, sensitive and private approach was made to Helen by the Disability Service Advisor to determine whether she wanted support during the programme. Following that initial discussion, the Disability Service initiated a meeting with the Practice Team to discuss Helen's placement needs. The SPF from the host trust was invited to engage in this discussion. This allowed for open discussions around reasonable adjustments in practice to start well in advance of Helen's practice placement.

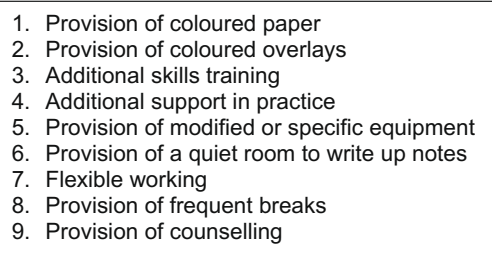

Fig. 5. Examples of reasonable adjustments.

The Practice Team, Disability Service and SPF adopted an approach that considered Helen's practical needs balanced against the statutory practice requirements of the programme. This ensured that Helen was able to gain a breadth of nursing experience whilst being sensitive to understanding her particular needs. Within the faculty, placements for disabled students are given priority during the planning phase, this enabled obstacles, such as transport and distance, to be removed from the overall decision-making process. A stable learning environment was selected in negotiation with the SPF, where Helen would be supported to develop coping strategies that would enable her to gain confidence in her clinical practice. This allowed Helen to capitalise on her strengths.

Reasonable adjustments in practice were considered. Examples are provided at Fig. 5. Minimal guidance as to what constitutes a reasonable adjustment is given, noting that the overriding concern is that the adjustment(s) should support a student to provide safe and effective practice. However, in practice the decisions are more common sense and practical than might be anticipated. In Helen's case, the following reasonable adjustments were made: regular breaks were to be taken and Helen was advised not to work long days or more than three shifts in a row.

Finally, to ensure appropriate support was provided by her mentor, Helen declared her disability with the support of the Practice Team. Therefore, the relevant link lecturer and mentor for each of her clinical placements were made aware of Helen's disability and the reasonable adjustments required. The mentor received appropriate preparation, including an advice sheet prepared by the Disability Service, and support to enable Helen to fully engage with the learning environment.

\section{Phase 3: mid-placement review; determine alternative strategies}

The mid-placement review involved the Practice Team, Disability Service and the SPF. A review of Helen's progress against the action plan was undertaken. Helen's mid-placement review was very positive and her overall progress encouraging. A review of the reasonable adjustments agreed at the beginning of the placement indicated that Helen could gradually introduce greater flexibility into her work patterns. In this particular case, no additional reasonable adjustments were needed.

Phase 4: development of detailed plans and models of support; establish critical information base

The aim of this phase is to develop a body of critical information based on the group's experiential learning of utilising an array of participatory support models for disabled students in practice. To do this, a student pathway analysis is undertaken by the group, which follows the student journey from pre-enrolment through to graduation. This enables analysis of key points in the student journey that leads to the formulation of detailed action plans and processes that could be developed and applied to different student situations. This exercise enables the formulation of evolving models of practice to aid critical judgements that can be made around reasonable adjustments. 
Phase 5: end of placement review; evaluation

The end review was undertaken by the group and designed to ensure effective management of the support framework in terms of achieving optimum student support in practice. Helen's pathway was discussed and analysed to identify which aspects of the support worked well and those which did not.

Helen's end of placement review was very positive, with favourable comments on her performance, progress and professional attitude offered by her mentor and link lecturer. Helen was asked to evaluate the support provided for them. She found her practice less arduous than anticipated and was confident that she could complete the programme as long as she continued to work on those coping strategies that had been developed for and by her.

\section{Phase 6: review support strategy}

Evaluation of the enabling model allowed for critical discussion between all members of the group and ensured that the support provided for Helen was sufficiently flexible to continue to meet her changing needs during the programme. The support strategy was reviewed by the group and Helen was invited to participate. As she progressed through the programme small alterations were made to the working time arrangements, with Helen taking an active stance in this process as her confidence and coping strategies developed. She therefore became proactive in the practice setting and less dependant on external means for support.

\section{Supporting change: moving forward}

The modern healthcare arena means that nurses are working under the stress of continuous service change, with the focus being on the achievement of targets and managing, with often less than optimal staff resources, to deliver complex patient care and treatment regimes. Against this backdrop mentoring disabled students may be seen as yet another initiative that must be incorporated into their busy schedule. There may be a great deal of resistance to this, resulting in negative attitudes being voiced by staff, "why should someone do nursing if they have poor memory recall or have difficulty reading and need more time to understand instructions?", with the overall perception being that the student is backward, lazy or slow (Riddick, 2000). There is a risk that disabled students who disclose a disability will become stigmatised, causing them to become isolated and to lose confidence. Anecdotal evidence suggests that practice staff have limited awareness of specific learning needs of disabled students and the workplace adjustments required to support them in practice.

It is argued that a combination of information, education and supported contact with a disabled person can result in positive attitudes towards disability (Happell, 2000; Chan and Cheng, $2001)$. In order to raise disability awareness within the University, a number of mediums have been used (Fig. 6) and the mentorship preparation and update programmes have been developed to incorporate information around supporting disabled students. A scenario-based approach is taken which allows mentors to discuss their concerns and the issues around supporting disabled students in practice. This forum allows exploration and discussion around

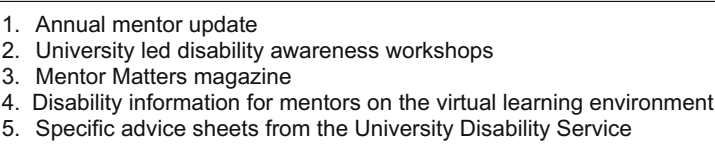

Fig. 6. Disability awareness activities. the requirements of special educational needs, the DDA and how it applies in practice.

A positive cultural change in terms of attitudes towards disabled students in practice will be a gradual process and is more likely to happen when there are positive case studies that illustrate their ability to function as an effective and valued member of the team. It is important that mentors recognise that a disability should not be used as a label to define the person. Having an identified disability should be treated no differently to any other challenge within the workplace. The student is likely to have strengths in other areas of practice and therefore has much to contribute to the team. In addition, mentors need to feel that they are not shouldering the perceived burden; they need to be supported effectively by both university and practice staff. Effective mentoring in practice is central to the success of this model.

The team acknowledge that a student's decision to disclose their disability is complex, and often results in a trade off between the perceived risks and benefits (Mental Health Foundation, 2002; Goode, 2007). However, unlike students undertaking a conventional Higher Education programme, pre-registration nursing students will have to disclose to multiple placements in a range of settings (Sapey et al., 2004; Furness and Gilligan, 2004; Morris and Turnbull, 2007). Thus, disclosure for these students is not seen as a finite event, but as a series of decisions and steps that have to be taken throughout the programme, each of which has to be managed (Stanley et al., 2007). The recurring nature of disclosure can be a significant challenge for disabled students.

In the last 2 years, we have witnessed a positive shift in the climate and atmosphere surrounding disclosure; key to this is the move to a positive organisational culture towards disabilities (Stanley et al., 2007). Many factors have influenced this change. In particular, the collaborative approach by the Practice Team, the Disability Service and the SPF has had a significant impact on practice support for disabled students. Primarily, this came out of the understanding that neither party can see the complete picture in isolation. To fully support the student, a collective approach was required; this led to earlier awareness and action. For example, the Faculty has adopted early identification methods, such as questionnaires that screen for dyslexia. Personal tutors are encouraged to proactively observe for, discuss and evaluate the likely presence of disabilities and refer students for assessment faster than might otherwise occur. The intention is to identify a student with additional needs as early as possible, to discuss their wishes and to facilitate an assessment that identifies the type of support required from an academic and practice perspective.

Another key factor is the on-going education of faculty staff to ensure we are able to improve the education provision for disabled students. Disability awareness training is provided by the university and all staff are actively encouraged to attend the training. Such training includes legal and professional requirements, university policies, systems and processes to identify, accommodate and evaluate reasonable adjustments and learning strategies to support students in the academic and practice setting.

\section{Conclusion}

A process of reflective learning through the use of student pathway analysis has enabled the group to continue to co-develop the framework. It is vital that the adjustment is tailored to the student's needs, rather than adopting a one model fits all approach, or making an assumption that a diagnosis will present in the same way (Stanley et al., 2007). A participatory approach was adopted in the case study as Helen was in the best position to describe and anticipate the type of support she required. There is rarely a right answer to a complex situation. However, if a systematic model is 
followed, a professional and structured approach can be taken and a course of action selected based on best evidence.

In order that a prepared and planned approach to practice can be achieved, a proactive and anticipatory stance should be taken to support disabled students in practice. The over-arching tenet is that disabled students are enabled, as far as possible, to achieve their full potential in the practice setting, through a collaborate partnership. It is axiomatic that the principles of co-construction, development and evaluation through reflexive discourse are used to ensure that the tripartite model of working remains dynamic and responsive to the changing demands of the student and practice.

Disabled students must work positively alongside university and practice staff to ensure the support framework addresses their needs appropriately. Specific preparation of mentors and link lecturers prior to the disabled student entering the clinical environment is vital. On-going disability awareness training and education for university and practice staff is also key to bringing about a positive change in culture. Opportunities for shared learning with other universities and healthcare providers, on a national and international basis, to enable the dissemination of good practice to inform the development of robust supportive models will greatly benefit disabled students.

\section{References}

Atkinson, K., Hutchinson, J.O., 2005. Visually impaired physiotherapists: challenging professional attitudes. International Congress Series 1281 (1), 908-912.

Ashcroft, T.J., Chernomas, W.M., Davis, P.L., Dean, R.A.K., Seguire, M., Shapiro, C.R., Swiderski, L.M., 2008. Nursing students with disabilities: one faculty's journey. International Journal of Nursing 5 (1), 1-15.

Bradshaw, M.J., Salzer, J.S., 2003. The nursing student with attention deficit hyperactivity disorder. Nurse Educator 28 (4), 161-165.

Buckinghamshire New University, 2007. Student services annual report. Buckinghamshire New University, High Wycombe.

Chan, S., Cheng, B.S., 2001. Creating positive attitudes: the effects of knowledge and clinical experience of psychiatry in student nurse education. Nurse Education Today 21 (6), 434-443.

Crawshaw, M., 2002. Disabled people's access to social work education-ways and means of promoting environmental change. Social work education 21 (5), 503-514.

Disability Rights Commission, 2007. Maintaining standards: promoting equality. DRC, Stratford-on-Avon.

Fleming, S., 2005. Nurses with disabilities: fear of discrimination still exists, but laws and technology create inroads. American Journal of Nursing 105 (6), 25-26.

Furness, S., Gilligan, P., 2004. Fit for purpose: issues for practice placements, practice teaching and the assessment of students' practice. Social Work Education 23 (4), 465-479.

Goode, J., 2007. Managing' disability: early experiences of university students with disabilities. Disability and Society 22 (1), 35-48.

Happell, B., 2000. Can education make a difference to undergraduate nursing students' attitude to psychiatric nursing? Contemporary Nurse 9 (1), 40-50.

Higher Education Statistics Agency, 2009. Student tables: disability. 2006/07. 2005/ 06 and 2004/05. www.hesa.ac.uk/holisdocs/pubinfo/stud.htm (01.02.2009).
HMSO, 1995. Disability Discrimination Act. London, HMSO.

HMSO, 2005. Disability Discrimination Act. London, HMSO.

HMSO, 2001. Special education needs and disability act 2001 (amendment) chapter 10. London, HMSO.

Ijiri, L., Kudzma, E., 2000. Supporting nursing students with learning disabilities: a metacognitive approach. Journal of Professional Nursing 16 (3), 149-157.

Konur, O., 2002. Assessment of disabled students in higher education: current public policy issues. Assessment Evaluation Higher Education 22 (7), 131-152.

Magilvy, J.K., Mitchell, A.C., 1995. Education needs of nursing students with special needs. Journal of Nursing Education 22 (?), 34, 3135.

Maheady, D.C., 2003. Nursing students with disabilities: change the course. Exceptional Parent Press, New Jersey.

Manthrope, J., Stanley, N., 1999. Dilemmas in professional education: responding effectively to students with mental health problems. Journal of Interprofessional Care 31 (4), 355-365.

Mental Health Foundation, 2002. Out of work: a survey of experiences of people with mental health problems within the workplace. MHF, London.

Morris, D., Turnbull, P.A., 2006. Clinical experiences of students with dyslexia. Journal of Advanced Nursing 54 (2), 238-247.

Morris, D.K., Turnbull, P.A., 2007. The disclosure of dyslexia in clinical practice: experiences of student nurses in the United Kingdom. Nurse Education Today $27,35-42$.

Nursing and Midwifery Council, 2004. Standards of proficiency for pre-registration nursing education. NMC, London.

Nursing and Midwifery Council, 2008. The code: standards of conduct, performance and ethics for nurses and midwives. NMC, London.

Riddick, B., 2000. An examination of the relationship between labelling and stigmatisation with special reference to dyslexia. Disability Society 15 (4), 653667.

Roberts, D., Mitchell, D., 2005. Problem-based learning in nurse education: an unexpected problem for students with dyslexia. Nurse Education in Practice 5 (6), 328-332

Ryan, J., Struhs, J., 2004. University education for all? Barriers to full inclusion of students with disabilities in Australian universities. International Journal of Inclusive Education 8 (1), 73-90.

Sanderson-Mann, J., McCandless, F., 2006. Understanding dyslexia and nurse education in the clinical setting. Nurse Education in Practice 6 (3), 127-133.

Sapey, B., Turner, R., Orton, S., 2004. Access to practice: overcoming the barriers to practice learning for disabled social work students. University of Southampton, Southampton.

Scullion, P., Brothers, M., Eathorne, V., 2002. Education for all. Learning Disability Practice 5 (2), 8-10.

Selekman, J., 2002. Nursing students with learning disabilities. Journal of Nursing Education 41 (8), 334-338.

Sowers, J., Smith, M.R., 2002. Disability as a difference. Journal of Nursing Education $41(8), 331-332$.

Stanley, N., Ridley, J., Manthorpe, J., Harris, J., Hurst, A., 2007. Disclosing disability: disabled students and practitioners in social work, nursing and teaching. Preston, UCLAN.

Watkinson, S., 2002. Dyslexia is a cause for concern in nursing. Nursing Standard 16 (32), 30.

White, J., 2007. Supporting nursing students with dyslexia in clinical practice. Nursing standard 21 (19), 35-42.

Wiles, J., 2001. In good company: why people with dyslexia should not be barred from nursing. Nursing Standard 15 (48), 23.

Wright, D., 2000. Education support for nursing and midwifery students with dyslexia. Nursing Standard 14 (41), 35-41.

Wright, D., Eathorne, V., 2003. SENDA: the implications of educating healthcare students and higher education, Dec 2-3, Manchester. SKILL conference http:// www.skill.org.uk (15.05.2008). 